\title{
BMJ Open Global prevalence and trends in hypertension and type 2 diabetes mellitus among slum residents: a systematic review and meta-analysis
}

\author{
Olalekan Abdulrahman Uthman (D) , ${ }^{1}$ Abimbola Ayorinde (D) , ${ }^{2}$ Oyinlola Oyebode, ${ }^{1}$ \\ Jo Sartori, ${ }^{3}$ Paramjit Gill, ${ }^{2}$ R J Lilford ${ }^{3}$
}

To cite: Uthman $\mathrm{OA}$, Ayorinde $\mathrm{A}$, Oyebode 0 , et al. Global prevalence and trends in hypertension and type 2 diabetes mellitus among slum residents: a systematic review and meta-analysis. BMJ Open 2022;12:e052393. doi:10.1136/ bmjopen-2021-052393

- Prepublication history and additional supplemental material for this paper are available online. To view these files, please visit the journal online (http://dx.doi.org/10.1136/ bmjopen-2021-052393).

Received 15 April 2021 Accepted 26 January 2022

D) Check for updates

(c) Author(s) (or their employer(s)) 2022. Re-use permitted under CC BY. Published by BMJ.

${ }^{1}$ Warwick Centre for Global Health, Warwick Medical School, University of Warwick, Coventry, UK

${ }^{2}$ Division of Health Sciences, Warwick Medical School, University of Warwick, Coventry, UK

${ }^{3}$ Institute of Applied Health

Research, University of

Birmingham, Birmingham, UK

\section{Correspondence to}

Professor Olalekan Abdulrahman Uthman;

olalekan.uthman@warwick. ac.uk

\section{ABSTRACT}

Objective First, to obtain regional estimates of prevalence of hypertension and type 2 diabetes in urban slums; and second, to compare these with those in urban and rural areas.

Design Systematic review and meta-analysis.

Eligibility criteria Studies that reported hypertension prevalence using the definition of blood pressure $\geq 140 / 90 \mathrm{~mm} \mathrm{Hg}$ and/or prevalence of type 2 diabetes. Information sources Ovid MEDLINE, Cochrane CENTRAL and EMBASE from inception to December 2020.

Risk of bias Two authors extracted relevant data and assessed risk of bias independently using the Strengthening the Reporting of Observational Studies in Epidemiology guideline.

Synthesis of results We used random-effects metaanalyses to pool prevalence estimates. We examined time trends in the prevalence estimates using meta-regression regression models with the prevalence estimates as the outcome variable and the calendar year of the publication as the predictor.

Results A total of 62 studies involving 108110 participants met the inclusion criteria. Prevalence of hypertension and type 2 diabetes in slum populations ranged from $4.2 \%$ to $52.5 \%$ and $0.9 \%$ to $25.0 \%$, respectively. In six studies presenting comparator data, all from the Indian subcontinent, slum residents were $35 \%$ more likely to be hypertensive than those living in comparator rural areas and $30 \%$ less likely to be hypertensive than those from comparator non-slum urban areas.

Limitations of evidence Of the included studies, only few studies from India compared the slum prevalence estimates with those living in non-slum urban and rural areas; this limits the generalisability of the finding. Interpretation The burden of hypertension and type 2 diabetes varied widely between countries and regions and, to some degree, also within countries.

PROSPERO registration number CRD42017077381.

\section{INTRODUCTION}

Non-communicable diseases (NCDs) are currently the leading cause of death globally; even in low/middle-income countries (LMICs), the burden of disease is shifting
Strengths and limitations of this study

- To reduce the chance of missing relevant studies, no language constraints were applied during the literature search.

- The data were extracted by two independent reviewers, reducing the possibility of bias.

- We analysed trends over time, and between geographical regions.

- The substantial between-studies heterogeneity is an important limitation.

- Of the included studies, only few studies from India compared the slum prevalence estimates with those living in non-slum urban and rural areas; this limits the generalisability of the finding.

from infectious diseases to NCDs. ${ }^{1}$ NCDs now account for about 41 million deaths annually, corresponding to nearly 7 in 10 of all deaths worldwide. Every year, 15 million people of ages 30-69 years die from these diseases, more than $85 \%$ of which are people living in LMICs. Most of the deaths from NCDs are caused by cardiovascular diseases, followed by cancer and respiratory diseases. NCDs affect people in all age groups, countries and geographical regions. The leading causes of these diseases include increased consumption of unhealthy foods, increased physical inactivity and population ageing. ${ }^{2-4}$ These factors are mediated through metabolic risk factors for NCDs, the most common of which include hypertension and type 2 diabetes. ${ }^{2-4}$

Urbanisation is a global phenomenon that is occurring at a fast pace in most LMICs. ${ }^{56}$ For more than 20 years, urban settlements have been increasing in population size because of fast growth in urban births, significant movement of people from rural areas and sustained integration of the global economy. ${ }^{5}$ The United Nations defines slums as urban areas with overcrowding, 
poor sanitation infrastructure, limited access to safe water, and/or poor structural quality of housing. ${ }^{78}$ Slums are now an important component of today's urban settlements and likely continue to be for the foreseeable future. $^{78}$

Despite increased global awareness about the presence and persistence of slums, and evidence that their populations are affected by different health problems and needs to other urban inhabitants, the health of their inhabitants is under-researched. ${ }^{7-10}$ The health of the urban poor, people with low socioeconomic status living in urban areas, is usually conflated with that of slum residents. Although there is substantial overlap between these groups, there are also richer residents within slum neighbourhoods, as well as urban poverty occurring in non-slum urban areas. Health outcomes for these two groups may differ depending on whether deprivation is at the individual (urban poverty) or neighbourhood level (slum resident) due to neighbourhood effects. ${ }^{781112}$ For example, with respect to NCD risk factors, those residents in slums, whatever their personal socioeconomic status, may be more exposed to common physical environmental risk factors (for example: air pollution increasing risk of hypertension), social environmental risk factors (for example: crime rates which may increase stress and drive metabolic risk) or institutional risk factors (for example: stigma on the basis of their address reducing access to appropriate medical care). Many existing studies of NCD risk factors done in urban areas do not disaggregate the population's health data by slum and non-slum status to allow for the detection of intraurban health disparities that are due to neighbourhood effects rather than individual socioeconomic status. ${ }^{13-22}$

Understanding how the global challenges of hypertension, type 2 diabetes and rapid unplanned urbanisation intersect, by investigating whether the up to 1 billion people residing in slums ${ }^{23}$ are succumbing to these important metabolic risk factors for NCD, will inform priorities for health services and health policy in LMICs. To fill this research gap, we therefore systematically gathered all the publications that relate to the burden of hypertension among slum residents to (1) assess the contemporary prevalence estimates of hypertension among slum residents; (2) compare the prevalence of hypertension and type 2 diabetes in slums with those in two other types of settlement, that is, non-slum urban and rural areas; and (3) assess the proportion of those with hypertension who were aware of their hypertensive status, those on treatment and those with blood pressure (BP) under control.

\section{METHODS}

\section{Protocol and registration}

The study background, rationale, and methods were specified in advance and documented in a protocol that was published in the PROSPERO register (CRD42017077381).

\section{Search and information sources}

We searched Ovid MEDLINE, Cochrane CENTRAL and EMBASE from inception to December 2020 using the following keywords: slum, shanty town, ghetto, hypertension and type 2 diabetes. The search strategy for MEDLINE is shown in online supplemental annex 1.

\section{Eligibility criteria}

We evaluated each identified study against the following predefined selection criteria:

- Types of studies: we included all studies (cross-sectional studies, retrospective or prospective cohort studies) that reported prevalence of hypertension and type 2 diabetes mellitus among slum residents as a primary or secondary outcome. No language, publication date or publication status restrictions were imposed.

- Types of participants: adult population (18 years and above) living in slums (as defined by the authors of the original studies included).

- Types of interventions: not applicable.

- Types of outcomes: essential hypertension (also called primary or idiopathic hypertension), defined as persistent (seated) systolic BP (SBP) of $140 \mathrm{~mm} \mathrm{Hg}$ or greater or had diastolic BP (DBP) $90 \mathrm{~mm} \mathrm{Hg}$ or greater regardless of age and sex. We excluded studies that included subjects with pregnancy-induced, preeclampsia, malignant, portal, pulmonary, renal, intracranial or ocular hypertension. We also excluded studies that used only self-reported measure, that is, deducible from the use of antihypertensive drugs or self-reported physician-diagnosed cases. If data were available, we noted (1) the percentage of those aware of their hypertension status, (2) on any antihypertensive treatment and (3) BP controlled to a target level. Awareness of hypertension was defined as selfreporting of any prior diagnosis of hypertension by a healthcare professional. Treatment of hypertension was defined as receiving prescribed antihypertensive medication for management of high BP at some time in the 1 year preceding the survey. Control of hypertension was defined as the proportion of patients reporting antihypertensive therapy with SBP of less than $140 \mathrm{~mm} \mathrm{Hg}$ and DBP of less than $90 \mathrm{~mm} \mathrm{Hg}$.

Type 2 diabetes was defined based on measured fasting plasma glucose, or oral glucose tolerance test. Type 2 diabetes was diagnosed if the fasting blood glucose was $\geq 126 \mathrm{mg} / \mathrm{dL}(\geq 7.0 \mathrm{mmol} / \mathrm{L})$ after an overnight fast for at least 8 hours, or random capillary blood glucose of $\geq 11.1 \mathrm{mmol} / \mathrm{L}$ or if the participant was taking treatment for type 2 diabetes.

\section{Study selection}

Two reviewers (OAU, AA) independently evaluated the eligibility and methodological quality of the studies obtained from the literature searches. All articles yielded by the database search were initially screened by their titles and abstracts to obtain studies that met inclusion criteria. In cases of discrepancies, agreement was reached 
by discussion with a third reviewer. Two reviewers (OAU, AA) independently evaluated the full-text articles of all identified citations to establish relevance of the article according to the prespecified criteria. In cases of discrepancies, agreement was reached by discussion with a third reviewer.

\section{Data collection process and data items}

OAU extracted data, and $\mathrm{AA}$ and $\mathrm{OO}$ checked the extracted data. For each study that met the selection criteria, details extracted included year of publication, country of origin, study design, sample size, sampling strategy, study period, setting (rural/urban/slum), sociodemographic variables, prevalence estimates, etc.

\section{Risk of bias (quality) assessment}

We used the Risk of Bias Assessment tool for Nonrandomized Studies ${ }^{24}$ to assess the risk of bias of included studies (see online supplemental box 1). The risk of bias in a study was graded as low, high or unclear on the basis of study features including the selection (selection of participants and confounding variables), performance (measurement of exposure), detection (blinding of outcome assessments), attrition (incomplete outcome data) and reporting (selective outcome reporting).

For each included study, we estimated the precision (C) or margin of error, considering the sample size (SS) and the observed prevalence (p) of hypertension among slum dwellers from the formula:

$$
\mathrm{SS}=\mathrm{Z}^{2} \times \mathrm{p} \times(1-\mathrm{p}) / \mathrm{C}^{2}
$$

where $\mathrm{Z}$ was the $\mathrm{Z}$-value fixed at 1.96 across studies (corresponding to $95 \% \mathrm{CI}$ ). The desirable margin of error is $5 \%(0.05)$ or lower.

\section{Synthesis of results}

For the meta-analysis, we used DerSimonian-Laird random-effects model ${ }^{25}$ due to anticipated variations in study population, healthcare delivery systems and stage of epidemic transition to pool the hypertension and type 2 diabetes prevalence estimates. We performed leave-onestudy-out sensitivity analysis to determine the stability of the results. ${ }^{26}$ This analysis evaluated the influence of individual studies by estimating the pooled prevalence estimates in the absence of each study. ${ }^{26}$ We assessed heterogeneity among studies by inspecting the forest plots and using the $\mathrm{X}^{2}$ test for heterogeneity with a $10 \%$ level of statistical significance and using the $\mathrm{I}^{2}$ statistic where we interpret a value of $50 \%$ as representing moderate heterogeneity. ${ }^{27}$ We assessed the possibility of publication bias by evaluating a funnel plot for asymmetry. Because graphical evaluation can be subjective, we also conducted an Egger's regression asymmetry test as formal statistical tests for publication bias. ${ }^{29}$

Following the overall analyses, we performed the following subgroup analyses: place of residence (rural vs urban slum vs non-slum urban); participants' risk factors, including socioeconomic position; study design (cross-sectional, cohort); study location (low/middleincome vs high-income countries) and study precision.

We examined time trends in the prevalence estimates using meta-regression regression models with the prevalence estimates as the outcome variable and the calendar year of the publication as the predictor. In order to measure secular patterns in prevalence figures, we use the annual average percentage change (AAPC). We fitted a regression line to the natural logarithm of the prevalence estimates, that is, $y=\alpha+\beta x+\varepsilon$, where $y=\ln$ (Prevalence), and $\mathrm{x}=$ calendaryear. The AAPC was calculated as $100 \times(\exp (\beta)-1)$. The $95 \% \mathrm{CI}$ of the AAPC was also computed from the regression model. ${ }^{30}$ The prevalence calculations indicated an upward trend when both the AAPC estimate and the lower limit of its $95 \%$ CI were $>0$. However, they indicated a downward trend when both the AAPC and its upper limits were less than 0 . The prevalence estimates were otherwise considered stable over time. ${ }^{30}$ This systematic review was reported according to the Preferred Reporting Items for Systematic Reviews and Meta-analyses guideline (online supplemental annex 2). ${ }^{31}$

\section{Patient and public involvement}

No patient was involved.

\section{RESULTS}

\section{Study selection and characteristics}

The literature search yielded 1490 articles. Online supplemental figure 1 shows the study selection flow diagram. After review, 135 articles were selected for critical reading. Seventy-two studies did not meet the inclusion criteria and were excluded (see online supplemental table 1 for list of excluded studies). The other 62 studies involving 108110 participants met the inclusion criteria and were included in the meta-analysis. ${ }^{13-22}$ 32-80 Forty-three studies reported only hypertension prevalence estimates, 29 studies reported only type 2 diabetes prevalence estimates and 8 reported both. Table 1 and online supplemental table 2 present the characteristics of the included studies. The studies were reported between 1989 and 2019. Studies were reported as fulltext journal articles $(n=61,98 \%)$; except for one which was reported as a conference abstract. The number of participants included in the studies ranged from 100 to 15763. When reported, the mean age of participants ranged from 32 years to 47 years. Most of the studies were carried out in South Asia: India $(n=30)$; Bangladesh $(n=8)$, Nepal $(n=1)$ and Pakistan $(n=1)$; followed by subSaharan Africa: Kenya $(n=9)$ and Nigeria $(n=4)$; Latin America and Caribbean: Brazil $(n=5)$ and Peru $(n=1)$; and East Asia and Pacific: Thailand $(n=1)$. Most of the studies were conducted in the following urban slums: Kibera $(n=4)$, Delhi $(n=3)$, Hyderabad $(n=3)$, Ajegunle $(n=2)$, Chandigarh $(n=2)$, Chennai $(n=2)$, Dhaka $(n=2)$, Haryana $(n=2)$ and Maceio $(n=2)$. 
Open access

Table 1 Pooled prevalence by different subgroups

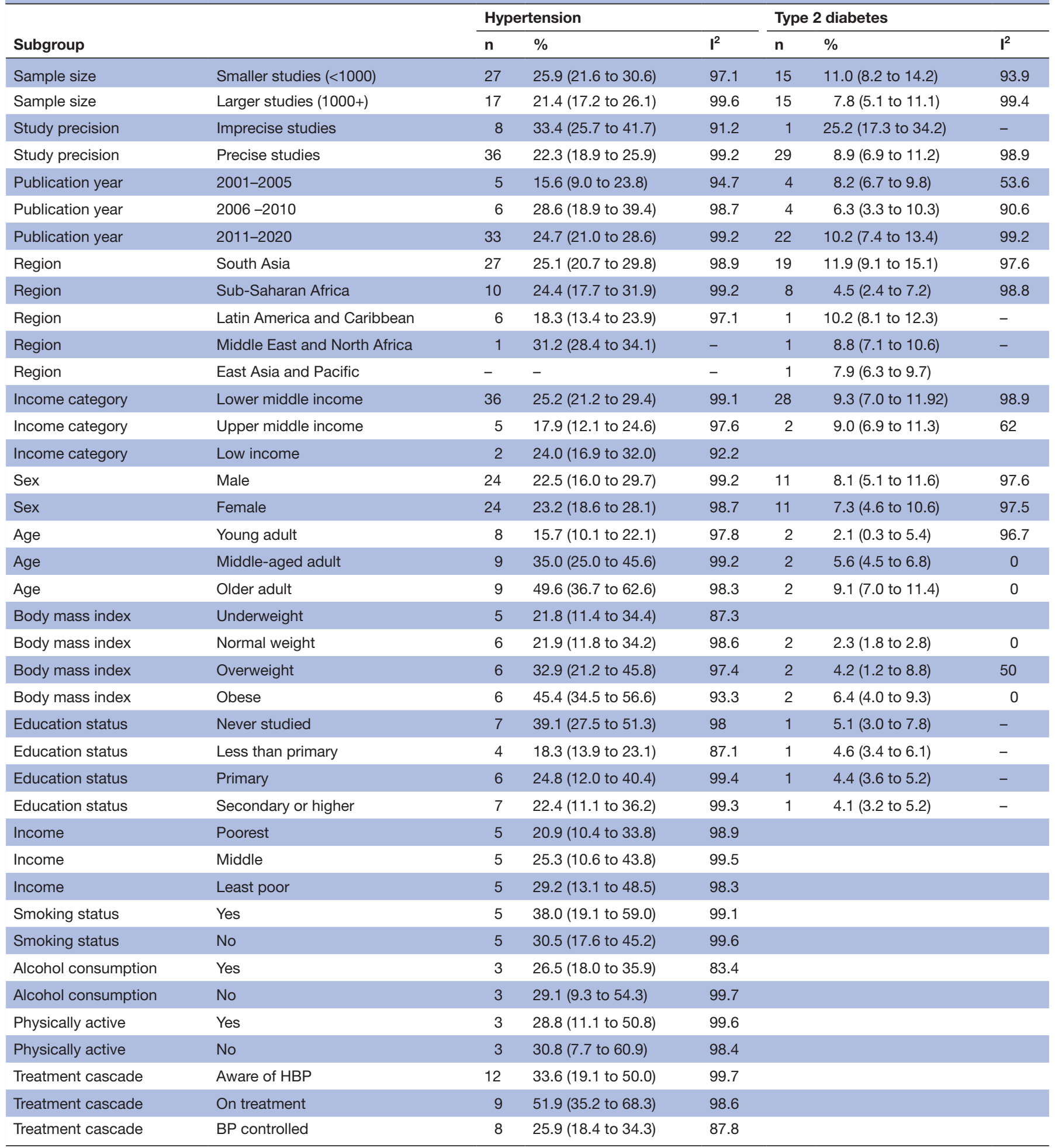

World Bank Country Income Groups, 2018.

Participants were divided into age groups that, broadly defined, covered young adulthood (18-35 years), middle age (36-55 years) and older adulthood (56 years and older).

Underweight-body mass index under $18.5 \mathrm{~kg} / \mathrm{m}^{2}$.

Normal weight-body mass index greater than or equal to $18.5-24.9 \mathrm{~kg} / \mathrm{m}^{2}$.

Overweight-body mass index greater than or equal to $25-29.9 \mathrm{~kg} / \mathrm{m}^{2}$.

Obesity-body mass index greater than or equal to $30 \mathrm{~kg} / \mathrm{m}^{2}$.

Physical activity as defined by authors.

Alcohol consumption as defined by authors.

Smoking status as defined by authors.

Income status as reported by authors.

$\mathrm{BP}$, blood pressure; HBP, high BP. 


\section{Risk of bias of included studies}

Summary of risk of bias assessment for each study is shown in online supplemental table 3 . The risk of bias in the selection of participants was low in most studies $(\mathrm{n}=56,90 \%)$, high in three studies $(5 \%)$ and unclear in three studies (5\%). Risk of bias due to confounding variables was low in most studies $(n=39,63 \%)$, high in 22 studies $(36 \%)$ and unclear in 1 study. Risk of bias due to measurement of exposure, blinding of outcome assessments and selective outcome reporting was low in all the 62 studies as we included all studies that used objective measure of hypertension and type 2 diabetes. Risk of bias due to incomplete outcome data was low in most studies $(\mathrm{n}=54,87 \%)$, high in two studies $(3 \%)$ and unclear in six studies $(10 \%)$.

\section{Variations in prevalence of hypertension and type 2 diabetes by geographical regions}

Prevalence of hypertension and type 2 diabetes from individuals is shown in figures 1 and 2 , respectively.

\section{East Asia and Pacific}

Thailand: one study from Klong-Toey slum found that 77 of the 976 respondents had type 2 diabetes in 1989 (7.9\%, $95 \%$ CI $6.3 \%$ to $9.8 \%$ ).

\section{Latin America and Caribbean}

Brazil: four studies reported the prevalence of hypertension from three different slums: Maceio $(n=2)$, Rio de Janeiro $(n=1)$ and Salvador $(n=1)$. Florencio et a $t^{42}$ found that almost one-third of the Maceio slum dwellers were hypertensive in 2004 (29.8\%, 95\% CI $24.8 \%$ to $35.2 \%)$, while Ferriera $e t a l^{41}$ estimated prevalence of hypertension among Maceio slum residents to be $14.8 \%$ (95\% CI $10.4 \%$ to $20.2 \%$ ) in 2005 . The reported prevalence of hypertension in other slums was $11.3 \%$ (95\% CI $10.2 \%$ to $12.4 \%$ ) in Rio de Janeiro in 2007 and $20.6 \%$ (95\% CI $19.5 \%$ to $21.7 \%$ ) in Salvador in 2015 . The pooled prevalence ('annualised year average') of hypertension for the four studies yielded an estimate of $18.4 \%$ (95\% CI $12.0 \%$ to $26.2 \%$ ). One study from Brazil found that 1 in $10 \mathrm{had}$ type 2 diabetes in 2017.

Peru: one study from a Lima slum conducted in 2014 found that 21 of the 142 respondents were hypertensive (14.8\%, $95 \%$ CI $9.4 \%$ to $21.7 \%)$.

\section{South Asia}

Bangladesh: four studies from Dhakan slums reported prevalence of hypertension. The reported prevalence of hypertension ranged from $11.6 \%(95 \%$ CI $9.7 \%$ to $13.8 \%$ ) in 2012 to $19.56 \%$ (95\% CI $17.85 \%$ to $21.37 \%$ ) in 2018. Five studies from Dhakan slums reported prevalence of type 2 diabetes. The pooled prevalence ('annualised year average') of hypertension for the three studies yielded an estimate of $16.1 \%$ (95\% CI $12.2 \%$ to $20.3 \%$ ). The reported prevalence of type 2 diabetes in these slums ranged from $8.1 \%$ (95\% CI $6.8 \%$ to $9.6 \%$ ) in 2004 to $18.12 \%$ (95\% CI $16.46 \%$ to $19.87 \%$ ) in 2019 .

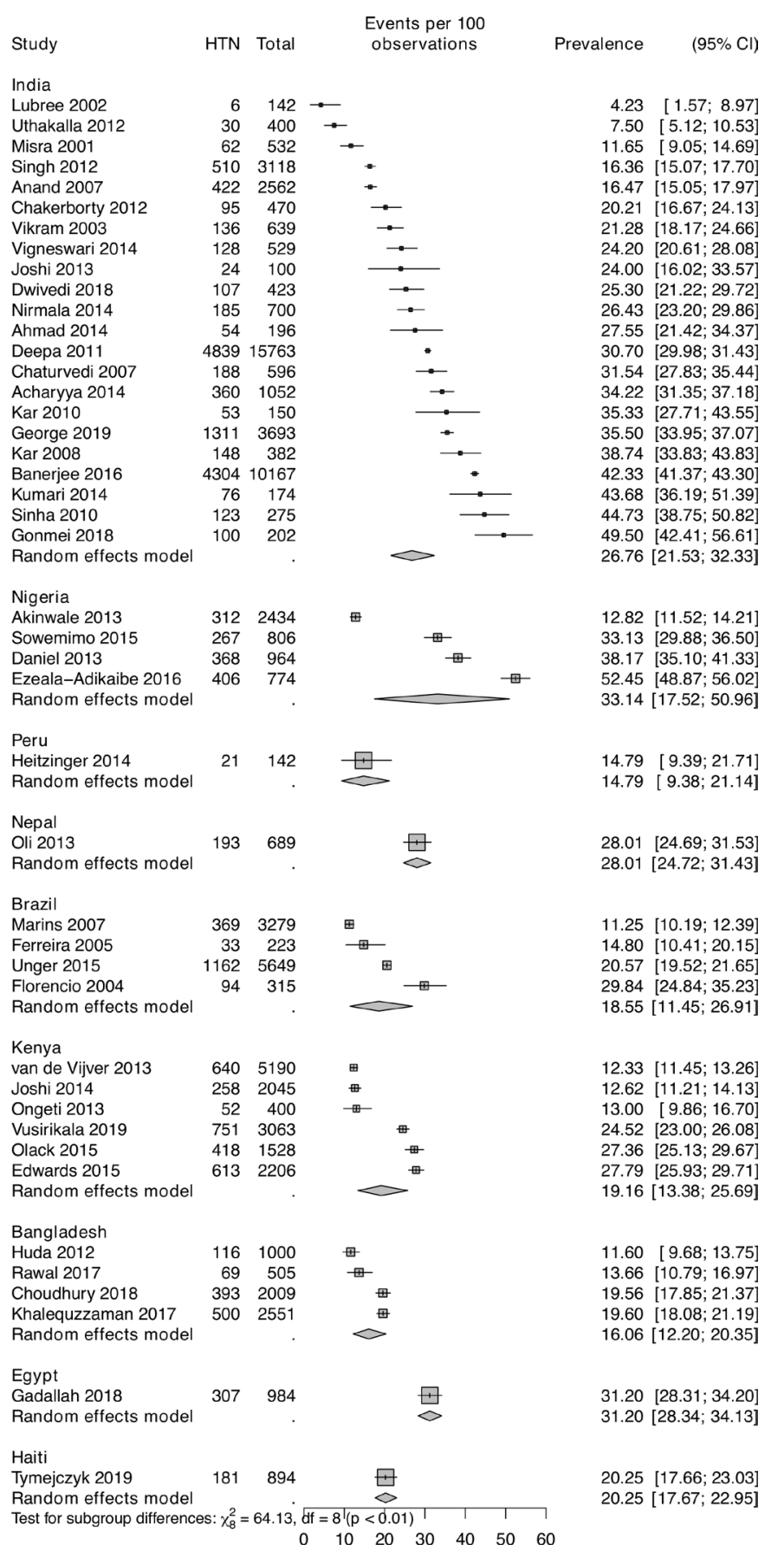

Figure 1 Hypertension (HTN) prevalence estimates among slum residents and $95 \%$ Cls from individual studies and pooled data.

India: 22 studies from India reported prevalence of hypertension from more than 15 different slums. The reported prevalence varied across and within the slums. For example, Kar et $a t^{48}$ estimated the prevalence of hypertension to be $27.6 \%$ (95\% CI $21.4 \%$ to $34.4 \%$ ) among 196 Chandigarh and Haryana slum residents in 2008; however, they estimated the prevalence of hypertension to be $16.5 \%$ (95\% CI $15.1 \%$ to $18.0 \%$ ) among 2 562196 Chandigarh and Haryana slum residents in 2010. Prevalence of type 2 diabetes also varied across slums in India. The pooled prevalence ('annualised year average') 


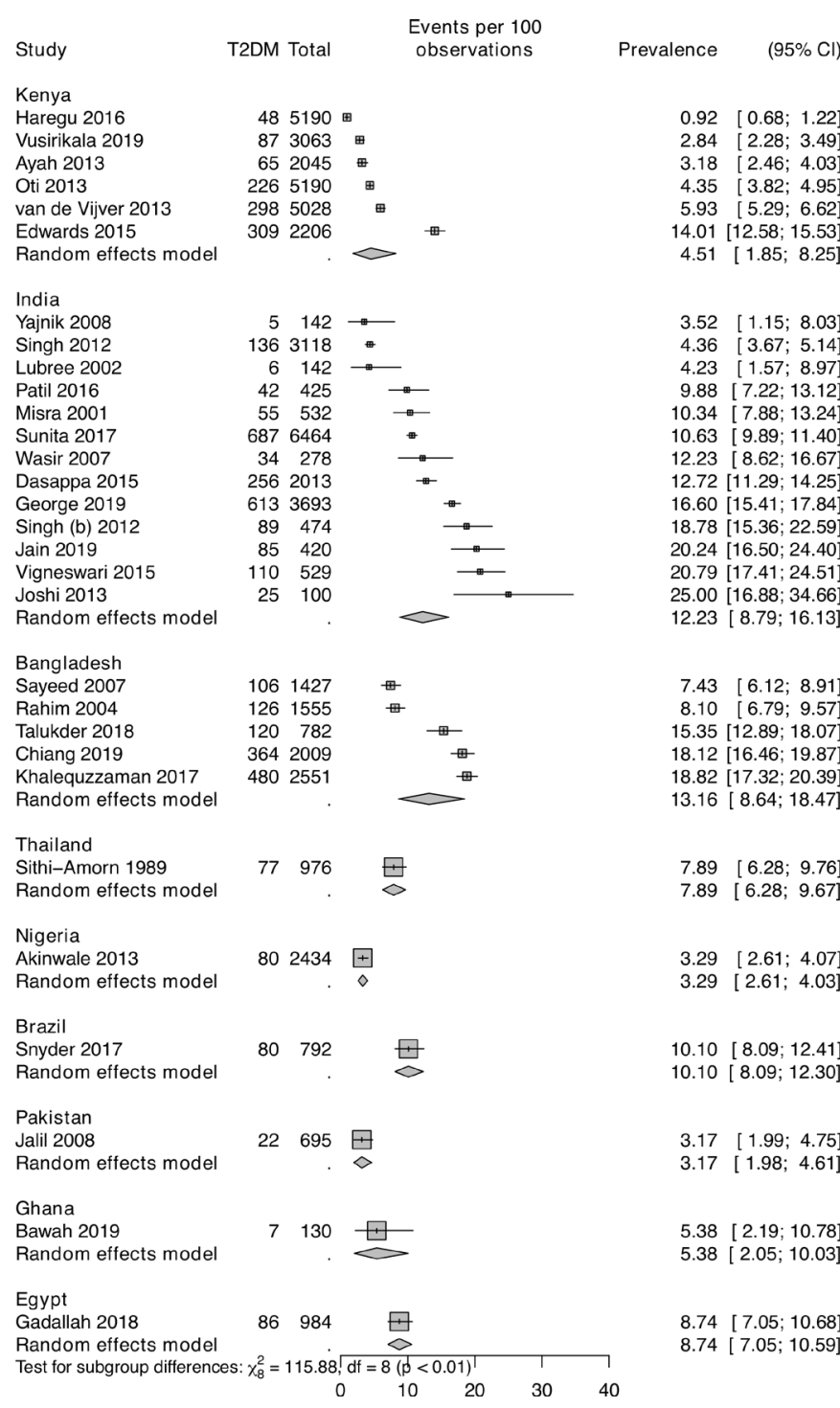

Figure 2 Type 2 diabetes mellitus (T2DM) prevalence estimates among slum residents and $95 \%$ Cls from individual studies and pooled data.

of hypertension for the 22 studies yielded an estimate of $26.8 \%$ (95\% CI $22.5 \%$ to $31.3 \%$ ). In Delhi, the reported prevalence of type 2 diabetes ranged from $12.7 \%$ (95\% CI $11.3 \%$ to $14.2 \%$ ) in 2007 to $31.5 \%$ (95\% CI $27.8 \%$ to $35.4 \%$ ) in 2012. The pooled prevalence ('annualised year average') of type 2 diabetes for the 13 studies yielded an estimate of $12.2 \%$ (95\% CI $9.2 \%$ to $15.6 \%$ ).

Nepal: one study from a Kathmandu slum conducted in 2013 found that 193 of the 689 respondents were hypertensive $(28.0 \%, 95 \%$ CI $24.7 \%$ to $31.5 \%)$.

Pakistan: one study from a Lahore slum found that 22 of the 695 respondents had type 2 diabetes in 2008 (3.2\%, 95\% CI $2.0 \%$ to $4.8 \%$ ).

Sub-Saharan Africa, Kenya: six studies reported the prevalence of hypertension from three different slums: Kibera $(n=4)$ and Viwandani and Korogocho $(n=2)$. The reported prevalence among Kibera slum residents ranged from $13.0 \%$ (95\% CI $9.9 \%$ to $16.7 \%$ ) in 2013 to $27.8 \%$ $(95 \%$ CI $25.9 \%$ to $29.7 \%)$ in 2015 . van de Vijver et $a b^{68}$ found that 640 of the 5190 respondents from Viwandani and Korogocho slums were hypertensive $(12.3 \%$, 95\% CI $11.5 \%$ to $13.3 \%$ ). The pooled prevalence ('annualised year average') of hypertension for the six studies yielded an estimate of $19.2 \%$ (95\% CI $13.2 \%$ to $26.0 \%$ ). The reported prevalence of type 2 diabetes ranged from $0.9 \%$ $(95 \%$ CI $0.7 \%$ to $1.2 \%)$ in Nairobi slum in 2016 to $4.4 \%$ (95\% CI $3.8 \%$ to $5.0 \%$ ) in Viwandani and Korogocho in 2013. The pooled prevalence ('annualised year average') of type 2 diabetes for the six studies yielded an estimate of $4.5 \%$ (95\% CI $2.0 \%$ to $7.9 \%$ ).

Nigeria: four studies from five different slums reported prevalence of hypertension. The reported prevalence varied across and within the slums. Ezeala-Adikaibe $e t a l^{40}$ found that half of the respondents from Enugu slums were hypertensive in $2016(52.5 \%, 95 \% \mathrm{CI} 48.9 \%$ to $56.0 \%)$. While Daniel et al and Sowemimo et al ${ }^{16}{ }^{64}$ found that almost one-third of the Ajegule (38.2\%, 95\% CI 35.1\% to $41.3 \%, 2013)$ and Yemetu $(33.1 \%, 95 \%$ CI $30.0 \%$ to $36.5 \%, 2015)$ slum residents were hypertensive. However, Akinwale $e t a l^{33}$ found that only $12.8 \%$ of the respondents from Ijora Oloye, Ajegunle and Makoko were hypertensive in 2013. The pooled prevalence ('annualised year average') of hypertension for the four studies yielded an estimate of $33.2 \%$ (95\% CI $15.6 \%$ to $53.5 \%$ ). Akinwale et al found that only $3.3 \%$ of the respondents from Ijora Oloye, Ajegunle and Makoko had type 2 diabetes in 2013.

\section{Secular trends in hypertension and type 2 diabetes prevalence estimates}

Secular trends in hypertension, in five countries for which there were data across multiple time points, and type 2 diabetes, in three countries in which we had data across multiple time points, among slum residents are shown in figures 3 and 4 . We observed a continuous increase in prevalence of hypertension among slum residents in four out of five countries. The increase is more pronounced in India, followed by Kenya and Bangladesh. The prevalence of hypertension increased by $204.6 \%$ from $11.7 \%$ in 2001 to $35.5 \%$ in 2019 in India. The prevalence of hypertension increased by $98.8 \%$ from $12.3 \%$ in 2013 to $24.5 \%$ in 2019 in Kenya. However, the results of the trend analysis showed statistically significant upward trends only in India, such that the prevalence of hypertension increased $+6.9 \%(95 \% \mathrm{CI}+2.0 \%$ to $+12.0 \%)$ per year between 2001 and 2019. There was no statistically significant trend observed in Brazil using trend analyses (trend $=-0.0 \%$, $95 \% \mathrm{CI}-22.7 \%$ to $+29.2 \%$ ). We also observed a continuous increase in prevalence of type 2 diabetes among slum residents in India and Bangladesh. The prevalence of type 2 diabetes increased by $123.6 \%$ from $8.1 \%$ in 2004 to $18.1 \%$ in 2019 in Bangladesh. The prevalence of type 2 diabetes increased by $95.8 \%$ from $10.3 \%$ in 2001 to $20.2 \%$ in 2019 in India. However, the results of the trend analysis showed statistically significant upward trends only in Bangladesh such that the prevalence of type 2 diabetes increased $+5.9 \%(95 \%$ CI $+1.1 \%$ to $+10.8 \%$ ) per year between 2004 and 2019. A non-statistically significant downward trend 


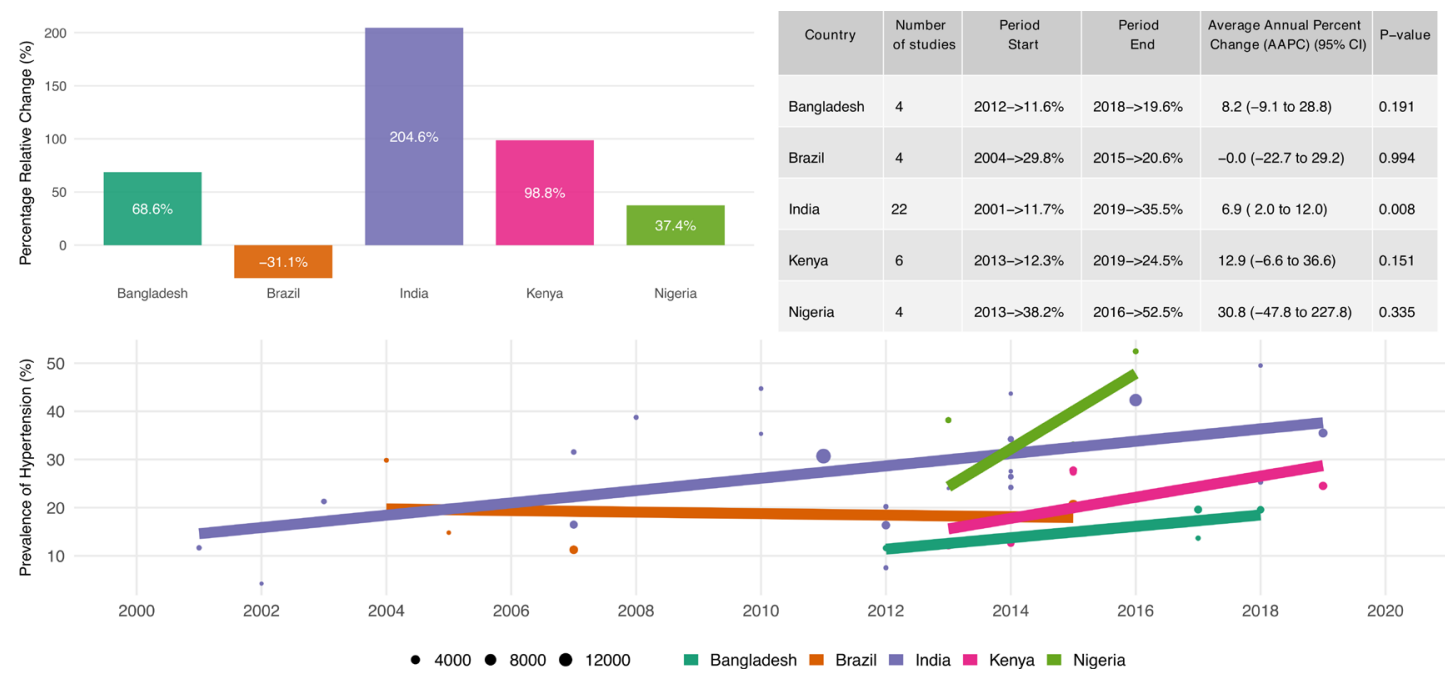

Figure 3 Secular trends in hypertension prevalence estimates among slum residents across different regions.

in type 2 diabetes prevalence was also observed in Kenya (trend $=-11.1 \%, 95 \%$ CI $-45.7 \%$ to $+45.6 \%$ ).

\section{Prevalence of hypertension by different hypertension and type} 2 diabetes subgroups

Study characteristics

As shown in table 1 , the pooled prevalence of hypertension was higher in studies conducted in lower middleincome countries $(23.2 \%, 95 \%$ CI $21.5 \%$ to $29.0 \%, 36$ studies) than those from upper middle-income countries ( $17.9 \%, 95 \%$ CI $12.1 \%$ to $24.6 \%, 5$ studies). The pooled prevalence of hypertension tended to be higher among studies from South Asia $(25.3 \%$, 95\% CI $21.3 \%$ to $29.6 \%$, 26 studies) and sub-Saharan Africa $(24.4 \%, 95 \%$ CI $17.7 \%$ to $31.9 \%, 10$ studies) than those from Latin America and Caribbean $(18.3 \%$, 95\% CI $13.4 \%$ to $23.9 \%, 6$ studies). The pooled prevalence tended to be higher among imprecise studies $(33.4 \%$, 95\% CI $25.7 \%$ to $41.7 \%, 8$ studies) than those from precise studies $(22.4 \%, 95 \%$ CI $18.9 \%$ to $26.1 \%$, 35 studies). The pattern was similar for type 2 diabetes prevalence estimates.

\section{Sociodemographic characteristics}

As shown in table 1 , the pooled prevalence of hypertension was similar among men $(22.5 \%, 95 \%$ CI $16.0 \%$ to $29.7 \%, 24$ studies) and women $(23.5 \%, 95 \%$ CI $18.6 \%$ to $28.1 \%, 24$ studies). The pooled prevalence of hypertension tended to be higher among older adults $(49.6 \%$, $95 \% \mathrm{CI} 36.7 \%$ to $62.6 \%, 9$ studies) than middle-aged (35.0\%, 95\% CI $25.0 \%$ to $45.6 \%, 9$ studies) and young adults $(15.7 \%, 95 \%$ CI $10.1 \%$ to $22.1 \%, 8$ studies). Similarly, the pooled prevalence of hypertension tended to be higher in obese $(45.4 \%, 95 \%$ CI $34.5 \%$ to $56.5 \%, 6$ studies) and overweight $(32.9 \%, 95 \%$ CI $21.2 \%$ to $45.8 \%$, 6 studies) participants than participants with normal (21.9\%, $95 \%$ CI $11.8 \%$ to $34.2 \%, 6$ studies) and underweight $(21.8 \%, 95 \%$ CI $11.4 \%$ to $34.4 \%, 5$ studies). The pooled prevalence of hypertension tended to be higher among those who never studied $(39.1 \%$, 95\% CI $27.5 \%$ to $51.3 \%)$ than those with less than primary $(18.3 \%$, $95 \%$ CI $13.9 \%$ to $23.1 \%$, 4 studies), primary (24.8\%, $95 \%$ CI $12.0 \%$ to $40.4 \%$, 6 studies) or secondary/higher

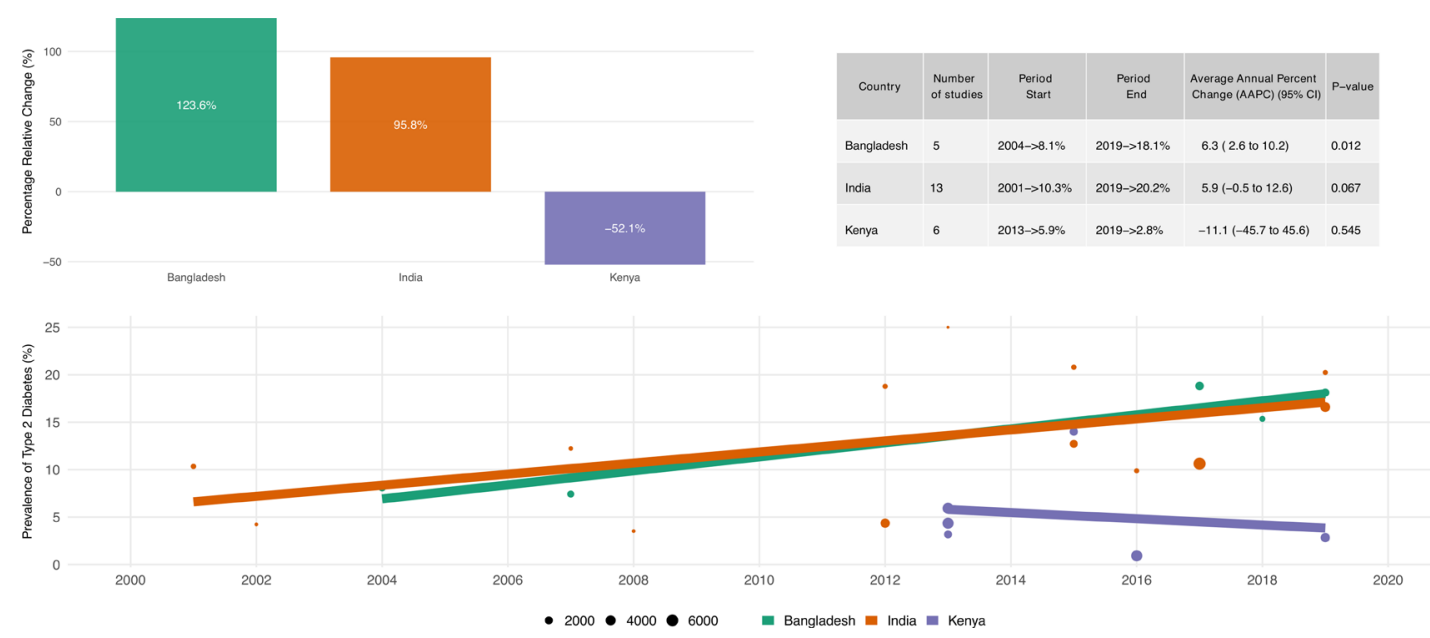

Figure 4 Secular trends in type 2 diabetes mellitus prevalence estimates among slum residents across different regions. 


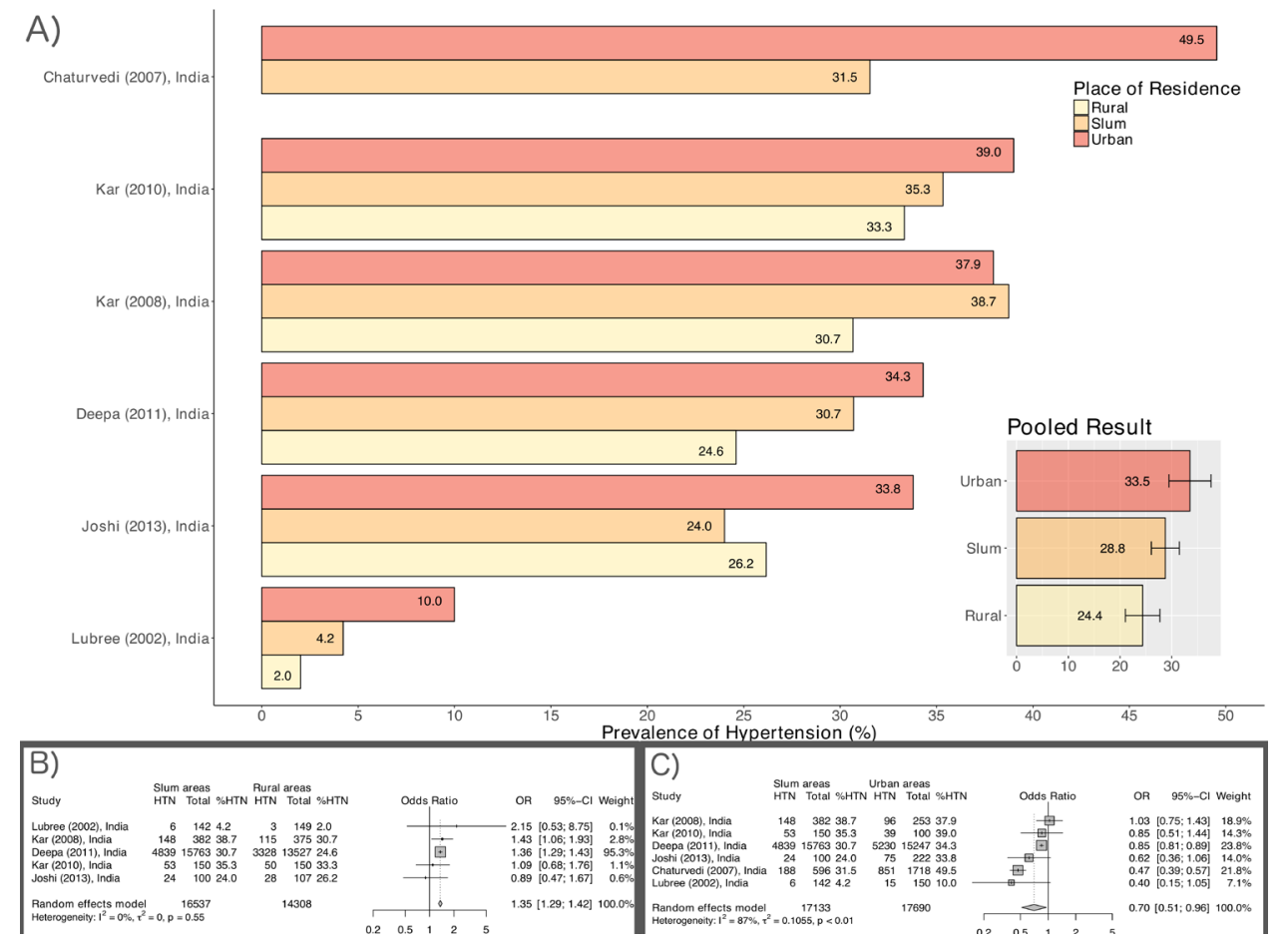

Figure 5 Hypertension (HTN) prevalence estimates by place of residence: urban versus rural versus slum. (A) Data from each studies, (B) Pooled estimates by place of residence, (C) Comparative pooled estimates.

educational attainment $(22.4 \%, 95 \%$ CI $11.2 \%$ to $36.2 \%$, 7 studies). The pooled prevalence of hypertension tended to be higher among the least poor $(29.2 \%, 95 \%$ CI $13.1 \%$ to $48.5 \%, 5$ studies) than those with middle $(25.3 \%$, 95\% CI $10.6 \%$ to $43.8 \%, 5$ studies) and poorest income ( $20.9 \%, 95 \%$ CI $10.4 \%$ to $33.8 \%, 5$ studies). The pattern was similar for type 2 diabetes prevalence estimates.

\section{Lifestyle factors}

The pooled prevalence of hypertension tended to be higher among smokers $(38.0 \%, 95 \%$ CI $19.1 \%$ to $59.0 \%, 5$ studies) than those not smoking $(30.5 \%, 95 \%$ CI $17.6 \%$ to $45.2 \%, 5$ studies). We found that the pooled prevalence of hypertension tended to be higher for those not physically active $(30.8 \%, 95 \%$ CI $7.7 \%$ to $60.9 \%, 3$ studies $)$ than those physically active $(28.8 \%, 95 \%$ CI $11.1 \%$ to $50.8 \%)$; tended to be higher among those with no history of alcohol consumption $(29.1 \%$, 95\% CI $9.3 \%$ to $54.3 \%$, 3 studies) than those who reported alcohol consumption (26.5\%, $95 \%$ CI $18.0 \%$ to $35.9 \%, 3$ studies).

\section{Comparative prevalence by place of residence}

Six studies from India included non-slum populations alongside data from the slum population, and reported prevalence of hypertension by place of residence. ${ }^{363846484951}$ As shown in figure 5, the pooled prevalence of hypertension was highest among those residing in non-slum urban areas $(33.5 \%, 95 \%$ CI $26.0 \%$ to $42.0 \%, 6$ studies), followed by urban slum residents (28.8\%, $95 \%$ CI $23.7 \%$ to $34.4 \%, 6$ studies) and was lowest among rural residents $(24.4 \%, 95 \%$ CI $18.4 \%$ to $31.5 \%$, 5 studies). Slum residents were $35 \%$ more likely to be hypertensive than those living in rural areas $(\mathrm{OR}=1.35$, 95\% CI 1.29 to 1.42 ) and $30 \%$ less likely to be hypertensive than those living in other urban areas $(\mathrm{OR}=0.70$, 95\% CI 0.51 to 0.96 ).

Four studies from India $(n=3)$ and Bangladesh reported prevalence of type 2 diabetes by place of residence. ${ }^{46} 515971$ As shown in figure 6 , the pooled prevalence of type 2 diabetes was highest among those residing in non-slum urban areas $(13.06 \%, 95 \%$ CI $6.53 \%$ to $24.43 \%$, 4 studies; 2813 participants), followed by urban slum residents $(7.88 \%, 95 \% \mathrm{CI} 3.32 \%$ to $17.55 \% ; 4$ studies; 1811 participants) and was lowest among rural residents (1.64\%; $95 \%$ CI $0.06 \%$ to $32.21 \%$; 3 studies; 405 participants). Prevalence of type 2 diabetes tended to be higher among urban slum residents than those living in rural areas (OR=3.78, 95\% CI 0.75 to 18.93). Urban slum residents were $46 \%$ less likely to be diabetic than those from other urban areas $(\mathrm{OR}=0.54,95 \% \mathrm{CI}$ 0.44 to 0.66 ).

\section{Treatment cascade}

Among those diagnosed with hypertension, only onethird were aware of their hypertensive status (33.6\%, $95 \%$ CI $19.1 \%$ to $50.0 \%, 12$ studies) (table 1 ). Among those aware of their high BP, half of them were on antihypertensive medications $(51.9 \%$, 95\% CI $35.2 \%$ to $68.3 \%$, 9 studies). Among those on treatment, only one-quarter had good BP control $(25.2 \%, 95 \%$ CI $18.4 \%$ to $34.3 \%, 8$ studies). Among those diagnosed with type 2 diabetes, $57.4 \%$ were aware of their type 2 diabetes status (95\% CI $18.2 \%$ to $91.8 \%, 2$ studies). 


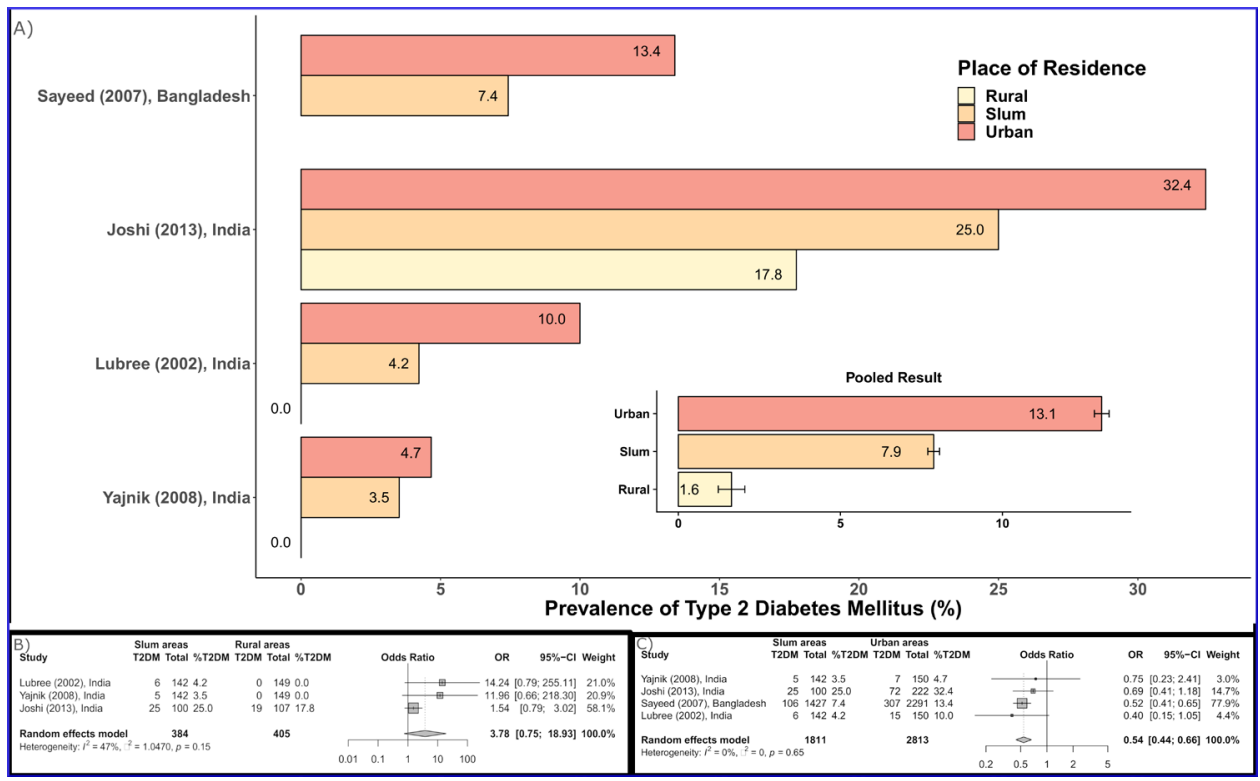

Figure 6 Type 2 diabetes mellitus (T2DM) prevalence estimates by place of residence: urban versus rural versus slum. (A) Data from each studies, (B) Pooled estimates by place of residence, (C) Comparative pooled estimates.

\section{DISCUSSION}

\section{Main findings}

This systematic review and meta-analysis summarises available evidence on the global prevalence of hypertension and type 2 diabetes among slum residents. There were several key findings: first, the burden of hypertension and type 2 diabetes among slum dwellers is high and may be rising globally, with wide variation between countries and regions and, to some degree, also within countries. Using data from within-study comparator populations when presented, the pooled prevalence of hypertension and type 2 diabetes was highest among those residing in nonslum urban areas, followed by slum residents, and was lowest among rural residents. This finding corroborates those of previous reviews that observed higher prevalence of hypertension among urban residents than those living in rural areas. ${ }^{81} 82$ This high prevalence may be due to rapid urbanisation, lifestyle changes, dietary changes and increased life expectancy, ${ }^{83} 84$ or a combination of these factors. ${ }^{85}$ In addition, the observed difference could be due to other factors including but not limited to lack of access to testing and care of NCD risk factors in rural areas and urban areas.

The observed gradient in burden of hypertension and type 2 diabetes among rural, slum and urban residents is consistent with the effects of urbanisation and wealth, as residents experience an economic transition when moving from one area to the next. ${ }^{87-92}$ LMICs are now undergoing epidemiological transition, the change from a burden of infectious diseases to chronic diseases. ${ }^{93}$ In addition, it could be due to increase in awareness in (nonslum) urban areas and recent availability of testing in some places. Recent systematic reviews of dietary risk behaviour in sub-Saharan Africa have found that urban populations tended to consume more salt than rural populations ${ }^{94}$ and consume fewer portions of vegetables. ${ }^{12}$ The rapid pace of urbanisation and economic growth is accelerating the rate of this epidemiological transition; as such LMICs are at great risk of an explosive growth in the burden of NCDs, including hypertension and type 2 diabetes. ${ }^{87} 88$

We found evidence of significant unmet need for hypertension care among urban slum residents. A significant proportion of the urban slum residents were unscreened, undiagnosed, untreated or uncontrolled. This huge unmet need has been documented in previous studies from low/middle-income settings. ${ }^{95-101}$ We also found that control of hypertension among slum residents was poor, such that only one in four slum residents on treatment had their BP controlled. The poor control of BP noted in our study, despite the fact the one-half of those who were unaware of high BP being on antihypertensive medications, needs further exploration. One possible explanation is availability and affordability of the medications and there could be minimal additional contact with a health professional. ${ }^{15}$ It has been documented that the control of BP was related to the frequency of follow-up visits ${ }^{96}$ Another possible explanation could be low adherence to prescribed medications, as they may not be able to afford the medications.

As expected, we found that the burden of hypertension increased with the particpants' age, which may be attributed to age-related structural changes in blood vessels which potentially cause narrowing of the vascular lumen, and consequently increasing BP, as have been reported in previous studies. ${ }^{102} 103$ The association between combined overweight/obesity and hypertension shown in our results exemplifies the role of excess body weight in hypertension prevalence, which has been long recognised and consistent across numerous observational and trial data. ${ }^{104-106}$ We found evidence of significantly high prevalence of hypertension among smokers compared with non-smokers. Direct relation of chronic 
tobacco consumption to hypertension however is not yet well established, ${ }^{107} 108$ although tobacco consumption has been shown to cause an acute elevation of BP. ${ }^{109}$

\section{Study limitations and strengths}

To the best of our knowledge, this paper is the first systematic review that summarises data about prevalence of hypertension and type 2 diabetes among slum residents. Strengths of this study include the use of a predefined and published protocol, a comprehensive search strategy and involvement of two independent reviewers in the review process. Nevertheless, the findings of this study should be interpreted with caution. Prevalence estimates from different regions and published over the course of 11 years were pooled in this meta-analysis, and as expected, high heterogeneity between studies was found in the meta-analyses. Nonetheless, as affirmed by previous evidence, meta-analyses are the preferred options to narrative syntheses for interpreting the results in a review, even in spite of the presence of a considerable amount of heterogeneity. ${ }^{110}$ Heterogeneity appeared to be the norm rather than exception in published meta-analyses of observational studies. ${ }^{111}$

In conclusion, the burden of hypertension and type 2 diabetes varied widely between countries and regions and, to some degree, also within countries. In addition, many individuals with hypertension are not aware of their condition, not on treatment and control of hypertension is poor. The burden of hypertension and type 2 diabetes was higher among urban residents than their counterparts living in urban slums and rural areas. There is a need for public health strategies to improve the awareness, control and overall management of hypertension and type 2 diabetes in urban areas.

Contributors $0 A U, A A, 00$ and RJL conceived the study. OAU, AA and 00 collected and analysed initial data. OAU, AA, 00, JS, PG and RJL participated in and contributed to refining the data analysis. OAU wrote the first manuscript. OAU, AA, $00, J S, P G$ and RJL contributed to further analysis, interpreting and shaping of the argument of the manuscript and participated in writing the final draft. OAU is the guarantor of this study.

Funding This research was funded by the National Institute for Health Research (NIHR) Global Health Research Unit on Improving Health in Slums using UK aid from the UK Government to support global health research (award ID: 16/136/87).

Disclaimer The views expressed in this publication are those of the author(s) and not necessarily those of the NIHR or the UK Department of Health and Social Care.

Competing interests None declared.

Patient consent for publication Not required.

Ethics approval This study does not involve human participants.

Provenance and peer review Not commissioned; externally peer reviewed.

Data availability statement All data relevant to the study are included in the article or uploaded as supplemental information.

Supplemental material This content has been supplied by the author(s). It has not been vetted by BMJ Publishing Group Limited (BMJ) and may not have been peer-reviewed. Any opinions or recommendations discussed are solely those of the author(s) and are not endorsed by BMJ. BMJ disclaims all liability and responsibility arising from any reliance placed on the content. Where the content includes any translated material, BMJ does not warrant the accuracy and reliability of the translations (including but not limited to local regulations, clinical guidelines, terminology, drug names and drug dosages), and is not responsible for any error and/or omissions arising from translation and adaptation or otherwise.

Open access This is an open access article distributed in accordance with the Creative Commons Attribution 4.0 Unported (CC BY 4.0) license, which permits others to copy, redistribute, remix, transform and build upon this work for any purpose, provided the original work is properly cited, a link to the licence is given, and indication of whether changes were made. See: https://creativecommons.org/ licenses/by/4.0/.

\section{ORCID iDs}

Olalekan Abdulrahman Uthman http://orcid.org/0000-0002-8567-3081

Abimbola Ayorinde http://orcid.org/0000-0002-4915-5092

\section{REFERENCES}

1 GBD 2016 Risk Factors Collaborators. Global, regional, and national comparative risk assessment of 84 behavioural, environmental and occupational, and metabolic risks or clusters of risks, 1990-2016: a systematic analysis for the global burden of disease study 2016. Lancet 2017;390:1345-422.

2 Bickler SW, Wang A, Amin S, et al. Urbanization in sub-Saharan Africa: declining rates of chronic and recurrent infection and their possible role in the origins of non-communicable diseases. World $\mathrm{J}$ Surg 2018;42:1617-28.

3 Goryakin Y, Rocco L, Suhrcke M. The contribution of urbanization to non-communicable diseases: evidence from 173 countries from 1980 to 2008. Econ Hum Biol 2017;26:151-63.

4 Khorrami Z, Etemad K, Yarahmadi S, et al. Urbanization and noncommunicable disease (Ncd) risk factors: who stepwise Iranian ncd risk factors surveillance in 2011. East Mediterr Health $J$ 2017;23:469-79.

5 Cohen B. Urban growth in developing countries: a review of current trends and a caution regarding existing forecasts. World Dev 2004;32:23-51.

6 Cohen B. Urbanization in developing countries: current trends, future projections, and key challenges for sustainability. Technol Soc 2006;28:63-80.

7 Ezeh A, Oyebode O, Satterthwaite D, et al. The history, geography, and sociology of slums and the health problems of people who live in slums. Lancet 2017;389:547-58.

8 Lilford RJ, Oyebode O, Satterthwaite D, et al. Improving the health and welfare of people who live in slums. Lancet 2017;389:559-70.

9 Riley LW, Ko Al, Unger A, et al. Slum health: diseases of neglected populations. BMC Int Health Hum Rights 2007;7:2.

10 Unger A, Riley LW. Slum health: from understanding to action. PLoS Med 2007;4:1561-6.

11 Lilford R, Kyobutungi C, Ndugwa R, et al. Because space matters: conceptual framework to help distinguish slum from non-slum urban areas. BMJ Glob Health 2019;4:e001267.

12 Mensah DO, Nunes AR, Bockarie T, et al. Meat, fruit, and vegetable consumption in sub-Saharan Africa: a systematic review and metaregression analysis. Nutr Rev 2021;79:651-92.

13 Ahmad S, Goel K, Parashar P, et al. A Community Based Cross Sectional Study on Life Style \& Morbidity Status of Elderly in Urban Slums of Meerut. Indian J Public Health Res Dev 2014;5:152-7.

14 Anand K, Shah B, Yadav K, et al. Are the urban poor vulnerable to non-communicable diseases? A survey of risk factors for noncommunicable diseases in urban slums of Faridabad. Natl Med $J$ India 2007;20:115-20.

15 Banerjee S, Mukherjee TK, Basu S. Prevalence, awareness, and control of hypertension in the slums of Kolkata. Indian Heart $J$ 2016;68:286-94.

16 Daniel OJ, Adejumo OA, Adejumo EN, et al. Prevalence of hypertension among urban slum dwellers in Lagos, Nigeria. $J$ Urban Health 2013;90:1016-25.

17 Heitzinger K, Montano SM, Hawes SE, et al. A community-based cluster randomized survey of noncommunicable disease and risk factors in a peri-urban shantytown in Lima, Peru. BMC Int Health Hum Rights 2014;14:19.

18 Nirmala DB, Vijay KM, Sreedhar M. Prevalence of risk factors for non communicable diseases in urban slums of Hyderabad. Telangana Indian Journal of Basic and Applied Medical Research 2014;4:487-93.

19 Oli N, Vaidya A, Thapa G. Behavioural risk factors of noncommunicable diseases among Nepalese urban poor: a descriptive study from a slum area of Kathmandu. Epidemiol Res Int 2013;2013:1-13. 
20 Rawal LB, Biswas T, Khandker NN, et al. Non-Communicable disease (Ncd) risk factors and diabetes among adults living in slum areas of Dhaka, Bangladesh. PLoS One 2017;12:e0184967.

21 Singh R, Mukheriee M, Kumar R, et al. Study of risk factors of coronary heart disease in urban slums of Patna. Nepal $J$ Epidemiology 2012;2:205-12.

22 Vigneswari A, Manikandan R, Satyavani K. Prevalence of risk factors of diabetes among urban poor South Indian population. $J$ Assoc Physicians India 2015;63:32-4.

23 UN-Habitat. UN-Habitat urbanization and development: emerging futures. world cities report 2016. Nairobi Kenya, 2016.

24 Kim SY, Park JE, Lee YJ, et al. Testing a tool for assessing the risk of bias for nonrandomized studies showed moderate reliability and promising validity. J Clin Epidemiol 2013;66:408-14.

25 DerSimonian R, Laird N. Meta-Analysis in clinical trials. Control Clin Trials 1986;7:177-88.

26 Normand SL. Meta-Analysis: formulating, evaluating, combining, and reporting. Stat Med 1999;18:321-59.

27 Higgins JPT, Thompson SG. Quantifying heterogeneity in a metaanalysis. Stat Med 2002;21:1539-58.

28 Higgins JPT, Thompson SG, Deeks JJ, et al. Measuring inconsistency in meta-analyses. BMJ 2003;327:557-60.

29 Egger M, Davey Smith G, Schneider M, et al. Bias in meta-analysis detected by a simple, graphical test. BMJ 1997;315:629-34.

30 Clegg LX, Hankey BF, Tiwari R, et al. Estimating average annual per cent change in trend analysis. Stat Med 2009;28:3670-82.

31 Liberati A, Altman DG, Tetzlaff $\mathrm{J}$, et al. The PRISMA statement for reporting systematic reviews and meta-analyses of studies that evaluate healthcare interventions: explanation and elaboration. BMJ 2009;339:b2700.

32 Acharyya T, Kaur P, Murhekar MV. Prevalence of behavioral risk factors, overweight and hypertension in the urban slums of North 24 Parganas district, West Bengal, India, 2010. Indian J Public Health 2014;58:195-8.

33 Akinwale O, Oyefara J, Adejoh P. The benefits of using a community-engaged research approach to promote a healthy lifestyle in three Nigerian urban slums. Southern African Journal of Epidemiology and Infection 2014;29:48-50.

34 Ayah R, Joshi MD, Wanjiru R, et al. A population-based survey of prevalence of diabetes and correlates in an urban slum community in Nairobi, Kenya. BMC Public Health 2013;13:20.

35 Chakraborty R, Bose K. Comparison of body adiposity indices in predicting blood pressure and hypertension among slum-dwelling men in Kolkata, India. Malays J Nutr 2012;18:319-28.

36 Chaturvedi S, Pant M, et al, Neelam. Hypertension in Delhi: prevalence, awareness, treatment and control. Trop Doct 2007;37:142-5.

37 Dasappa H, Fathima FN, Prabhakar R, et al. Prevalence of diabetes and pre-diabetes and assessments of their risk factors in urban slums of Bangalore. J Family Med Prim Care 2015;4:399-404.

38 Deepa M, Pradeepa R, Anjana R, et al. Noncommunicable diseases risk factor surveillance: experience and challenge from India. Indian $J$ Community Med 2011;36:S50-6.

39 Edwards JK, Bygrave H, Van den Bergh R, et al. Hiv with noncommunicable diseases in primary care in Kibera, Nairobi, Kenya: characteristics and outcomes 2010-2013. Trans R Soc Trop Med Hyg 2015;109:440-6.

40 Ezeala-Adikaibe BA, Orjioke C, Ekenze OS, et al. PopulationBased prevalence of high blood pressure among adults in an urban slum in Enugu, South East Nigeria. J Hum Hypertens 2016;30:285-91.

41 Ferreira HDS, TMTDM F, MDAC F. Hypertension, abdomina obesity and short stature: aspects of nutritional transition within a shantytown in the city of Maceio (northeastern Brazil). Revista de Nutricao 2005:18:209-18.

42 Florêncio TT, Ferreira HS, Cavalcante JC, et al. Short stature, obesity and arterial hypertension in a very low income population in north-eastern Brazil. Nutrition, Metabolism and Cardiovascular Diseases 2004;14:26-33.

43 Haregu TN, Oti S, Ngomi N, et al. Interlinkage among cardiometabolic disease markers in an urban poor setting in Nairobi, Kenya. Glob Health Action 2016;9:pp 30626.

44 Huda MN, Alam KS. Prevalence of chronic kidney disease and its association with risk factors in disadvantageous population. Int $J$ Nephrol 2012;2012:1-7.

45 Jalil F, Moore SE, Butt NS, et al. Early-Life risk factors for adult chronic disease: follow-up of a cohort born during 1964-1978 in an urban slum of Lahore, Pakistan. J Health Popul Nutr 2008;26:12-21.

46 Joshi A, Puricelli Perin D, Arora M. Using portable health information Kiosk to assess chronic disease burden in remote settings. Rural Remote Health 2013;13:2279.
47 Joshi MD, Ayah R, Njau EK, et al. Prevalence of hypertension and associated cardiovascular risk factors in an urban slum in Nairobi, Kenya: a population-based survey. BMC Public Health 2014:14:1177.

48 Kar SS, Thakur JS, Jain S, et al. Cardiovascular disease risk management in a primary health care setting of North India. Indian Heart J 2008;60:19-25.

49 Kar SS, Thakur JS, Virdi NK, et al. Risk factors for cardiovascular diseases: is the social gradient reversing in northern India? Natl Med J India 2010;23:206-9.

50 Kumari SMV, Humaira B, Sreedhar M. A study on prevalence of hypertension in urban slum field practice area of osmania medical college - Hyderabad. Indian Journal of Basic and Applied Medical Research 2014;4:462-70.

51 Lubree HG, Rege SS, Bhat DS, et al. Body fat and cardiovascular risk factors in Indian men in three geographical locations. Food Nutr Bull 2002;23:146-9.

52 Marins VMR, Almeida RMVR, Pereira RA, et al. The association between socioeconomic indicators and cardiovascular disease risk factors in Rio de Janeiro, Brazil. J Biosoc Sci 2007;39:221-9.

53 Misra A, Pandey RM, Devi JR, et al. High prevalence of diabetes, obesity and dyslipidaemia in urban slum population in northern India. Int J Obes Relat Metab Disord 2001;25:1722-9.

54 Olack B, Wabwire-Mangen F, Smeeth L, et al. Risk factors of hypertension among adults aged 35-64 years living in an urban slum Nairobi, Kenya. BMC Public Health 2015;15:1251.

55 Ongeti K, Ogeng'o J, Pulei A. Blood pressure characteristics among slum dwellers in Kenya. Global Advanced Research 2013;2:80-5.

56 Oti SO, van de Vijver SJM, Agyemang C, et al. The magnitude of diabetes and its association with obesity in the slums of Nairobi, Kenya: results from a cross-sectional survey. Trop Med Int Health 2013;18:1520-30

57 Patil RS, Gothankar JS. Assessment of risk of type 2 diabetes using the Indian diabetes risk score in an urban slum of Pune, Maharashtra, India: a cross-sectional study. WHO South East Asia J Public Health 2016;5:53-61.

58 Rahim MA, Vaaler S, Keramat Ali SM, et al. Prevalence of type 2 diabetes in urban slums of Dhaka, Bangladesh. Bangladesh Med Res Counc Bull 2004;30:60-70.

59 Sayeed MA, Mahtab H, Khanam PA, et al. Prevalence of diabetes and impaired fasting glucose in urban population of Bangladesh. Bangladesh Med Res Counc Bull 2007;33:1-12.

60 Singh AK, Mani K, Krishnan A, et al. Prevalence, awareness, treatment and control of diabetes among elderly persons in an urban slum of Delhi. Indian J Community Med 2012;37:236-9.

61 Sinha P, Taneja DK, Singh NP, et al. Seasonal variation in prevalence of hypertension: implications for interpretation. Indian J Public Health 2010;54:7-10.

62 Sitthi-Amorn C, Chandraprasert S, Bunnag SC, et al. The prevalence and risk factors of hypertension in Klong Toey slum and Klong Toey government apartment houses. Int J Epidemiol 1989;18:89-94.

63 Snyder RE, Lopes LA, Tavares LCC, et al. O Dia de Dona Maria using technology and community based participatory research to improve healthcare delivery in a Brazilian urban slum. Ann Glob Health 2016;82:599.

64 Sowemimo I, Ajayi I, Akpa O. Prevalence of hypertension and associated factors among residents of Ibadan-North local government area of Nigeria. Journal of Hypertension 2016;13:67-75.

65 Sunita M, Singh AK, Rogye A, et al. Prevalence of diabetic retinopathy in urban slums: the Aditya Jyot diabetic retinopathy in urban Mumbai slums Study-Report 2. Ophthalmic Epidemiol 2017;24:303-10.

66 Unger A, Felzemburgh RDM, Snyder RE, et al. Hypertension in a Brazilian urban slum population. J Urban Health 2015;92:446-59.

67 Uthakalla VK, Kishore Kumar KJ, Jena SK. Prevalence study of overweight/obesity among adults (20-60yrs) of urban field practice area of osmania medical College, Hyderabad. Indian Journal of Public Health Research and Development 2012;3:250-3.

68 van de Vijver S, Oti S, Tervaert TC, et al. Introducing a model of cardiovascular prevention in Nairobi's slums by integrating a public health and private-sector approach: the scale-up study. Glob Health Action 2013;6:22510.

69 Vikram NK, Pandey RM, Misra A, et al. Non-obese (body mass index $<25 \mathrm{~kg} / \mathrm{m} 2$ ) Asian Indians with normal waist circumference have high cardiovascular risk. Nutrition 2003;19:503-9.

70 Wasir JS, Misra A, Vikram NK, et al. C-Reactive protein, obesity, and insulin resistance in postmenopausal women in urban slums of North India. Diabetes Metab Syndr 2007;1:83-9. 
71 Yajnik CS, Joglekar CV, Lubree HG, et al. Adiposity, inflammation and hyperglycaemia in rural and urban Indian men: coronary risk of insulin sensitivity in Indian subjects (crisis) study. Diabetologia 2008;51:39-46.

72 Choudhury S, Al-Shoaibi AAA, Khalequzzaman M, et al. A16358 hypertension detection, treatment and control rates in urban slum population in Bangladesh. J Hypertens 2018;36:e337-8.

73 Dwivedi S, Gonmei Z, Toteja GS, et al. Assessment of risk factors of hypertension among adults residing in urban slum of Delhi. Asian Journal of Pharmaceutical and Clinical Research 2018;11:405-7.

74 Gonmei Z, Dwivedi S, Singh Toteja G, et al. Prevalence of hypertension among elderly residing in slums of West. Asian Journal of Pharmaceutical and Clinical Research 2018;11:337-9.

75 Abhinav J. A study of prevalence of diabetes mellitus and its risk factors in the urban slum population of Gurugram. Indian Journal of Public Health Research \& Development 2019;10:141-5.

76 Bawah AT, Abaka-Yawson A, Seini MM, et al. Prevalence of diabetes among homeless and slum dwellers in Accra, Ghana: a survey study. BMC Res Notes 2019;12:572.

77 Gadallah M, Abdel Megid S, Mohsen A, et al. Hypertension and associated cardiovascular risk factors among urban slum dwellers in Egypt: a population-based survey. East Mediterr Health $\mathrm{J}$ 2018;24:435-42.

78 George CE, Norman G, Wadugodapitya A, et al. Health issues in a Bangalore slum: findings from a household survey using a mobile screening toolkit in Devarajeevanahalli. BMC Public Health 2019;19:456.

79 Tymejczyk O, McNairy ML, Petion JS, et al. Hypertension prevalence and risk factors among residents of four slum communities: population-representative findings from Port-auPrince, Haiti. J Hypertens 2019;37:685-95.

80 Vusirikala A, Wekesah F, Kyobutungi C, et al. Assessment of cardiovascular risk in a slum population in Kenya: use of World Health Organisation/International Society of Hypertension (WHO/ ISH) risk prediction charts - secondary analyses of a household survey. BMJ Open 2019;9:e029304.

81 Addo J, Smeeth L, Leon DA. Hypertension in sub-Saharan Africa: a systematic review. Hypertension 2007;50:1012-8.

82 Pereira M, Lunet N, Azevedo A, et al. Differences in prevalence, awareness, treatment and control of hypertension between developing and developed countries. J Hypertens 2009;27:963-75.

83 Gupta R, al-Odat NA, Gupta VP. Hypertension epidemiology in India: meta-analysis of 50 year prevalence rates and blood pressure trends. J Hum Hypertens 1996;10:465-72.

84 Mahmood SE, Prakash D, Srivastava JP, et al. Prevalence of hypertension amongst adult patients attending out patient department of urban health training centre, department of community medicine, era's Lucknow medical college and Hospital, Lucknow. J Clin Diagn Res 2013;7:652-6.

85 Amuna P, Zotor FB. Epidemiological and nutrition transition in developing countries: impact on human health and development. Proc Nutr Soc 2008;67:82-90.

86 Kroll M, Bharucha E, Kraas F. Does rapid urbanization aggravate health disparities? Reflections on the epidemiological transition in Pune, India. Glob Health Action 2014;7:23447.

87 Angkurawaranon C, Jiraporncharoen W, Chenthanakij B, et al Urbanization and non-communicable disease in Southeast Asia: a review of current evidence. Public Health 2014;128:886-95.

88 Cheema A, Adeloye D, Sidhu S, et al. Urbanization and prevalence of type 2 diabetes in southern Asia: a systematic analysis. J Glob Health 2014:4:010404.

89 Low W-Y, Lee Y-K, Samy AL. Non-Communicable diseases in the Asia-Pacific region: prevalence, risk factors and community-based prevention. Int J Occup Med Environ Health 2015;28:20-6.

90 Phipps ME, Chan KKL, Naidu R, et al. Cardio-metabolic health risks in Indigenous populations of Southeast Asia and the influence of urbanization. BMC Public Health 2015;15:47.
91 Siegel KR, Patel SA, Ali MK. Non-Communicable diseases in South Asia: contemporary perspectives. Br Med Bull 2014;111:31-44.

92 Streatfield PK, Khan WA, Bhuiya A, et al. Adult non-communicable disease mortality in Africa and Asia: evidence from indepth health and demographic surveillance system sites. Glob Health Action 2014;7:25365

93 Gaziano TA, Bitton A, Anand S, et al. Growing epidemic of coronary heart disease in low- and middle-income countries. Curr Probl Cardiol 2010;35:72-115.

94 Oyebode O, Oti S, Chen Y-F, et al. Salt intakes in sub-Saharan Africa: a systematic review and meta-regression. Popul Health Metr 2016;14:1.

95 Adeloye D, Basquill C. Estimating the prevalence and awareness rates of hypertension in Africa: a systematic analysis. PLoS One 2014;9:e104300.

96 Macia E, Duboz P, Gueye L. Prevalence, awareness, treatment and control of hypertension among adults 50 years and older in Dakar, Senegal. Cardiovasc J Afr 2012;23:265-9.

97 Mohan V, Deepa M, Farooq S, et al. Prevalence, awareness and control of hypertension in Chennai--The Chennai Urban Rural Epidemiology Study (CURES-52). J Assoc Physicians India 2007;55:326-32.

98 Pilav A, Doder V, Branković S. Awareness, treatment, and control of hypertension among adult population in the Federation of Bosnia and Herzegovina over the past decade. J Public Health Res 2014;3:323.

99 Supiyev A, Kossumov A, Utepova L, et al. Prevalence, awareness, treatment and control of arterial hypertension in Astana, Kazakhstan. A cross-sectional study. Public Health 2015;129:948-53.

100 Tailakh A, Evangelista LS, Mentes JC, et al. Hypertension prevalence, awareness, and control in Arab countries: a systematic review. Nurs Health Sci 2014;16:126-30.

101 Yazdanpanah L, Shahbazian H, Shahbazian H, et al. Prevalence, awareness and risk factors of hypertension in Southwest of Iran. $J$ Renal Inj Prev 2015;4:51-6.

102 Landahl S, Bengtsson C, Sigurdsson JA, et al. Age-Related changes in blood pressure. Hypertension 1986;8:1044-9.

103 Pinto E. Blood pressure and ageing. Postgrad Med J 2007;83:109-14.

104 Dyer AR, Elliott P, Shipley M. Body mass index versus height and weight in relation to blood pressure. findings for the 10,079 persons in the INTERSALT study. Am J Epidemiol 1990;131:589-96.

105 Folsom AR, Kushi LH, Anderson KE, et al. Associations of general and abdominal obesity with multiple health outcomes in older women: the lowa women's health study. Arch Intern Med 2000;160:2117-28.

$106 \mathrm{Hu}$ G, Barengo NC, Tuomilehto J, et al. Relationship of physical activity and body mass index to the risk of hypertension: a prospective study in Finland. Hypertension 2004;43:25-30.

107 Hu G, Barengo NC, Tuomilehto J. Correlation between cigarette smoking and blood pressure and pulse pressure among teachers residing in Shiraz, southern Iran. Iran Cardiovasc Res $J$ 2011;5:97-102.

108 Primatesta P, Falaschetti E, Gupta S, et al. Association between smoking and blood pressure: evidence from the health survey for England. Hypertension 2001;37:187-93.

109 Westman EC. Does smokeless tobacco cause hypertension? South Med J 1995;88:716-20.

110 loannidis JPA, Patsopoulos NA, Rothstein HR. Reasons or excuses for avoiding meta-analysis in forest plots. BMJ 2008;336:1413-5.

111 Higgins JPT. Commentary: heterogeneity in meta-analysis should be expected and appropriately quantified. Int J Epidemiol 2008;37:1158-60. 